\title{
Effects of formaldehyde on vascular endothelial growth factor, matrix metallopeptidase 2 and osteonectin levels in periodontal membrane and alveolar bone in rats
}

\author{
N. Laçin'1 , B.S. İzol2 ${ }^{2}$ M.C. Tuncer ${ }^{3}$, E. Gökalp Özkorkmaz ${ }^{4}$, B. Deveci ${ }^{5}$, E. Deveci ${ }^{4}$ \\ ${ }^{1}$ Department of Oral and Maxillofacial Surgery, Faculty of Dentistry, University of Katip Çelebi, Izmir, Turkey \\ ${ }^{2}$ Department of Periodontology, Faculty of Dentistry, University of Bingöl, Turkey \\ ${ }^{3}$ Department of Anatomy, Faculty of Medicine, University of Dicle, Diyarbakır, Turkey \\ ${ }^{4}$ Department of Histology and Embryology, Faculty of Medicine, University of Dicle, Diyarbakır, Turkey \\ ${ }^{5}$ Department of Periodontology, Faculty of Dentistry, University of Dicle, Diyarbakir, Turkey
}

[Received: 8 October 2018; Accepted: 30 October 2018]

Background: The objective of this study was to investigate whether long term formaldehyde inhalation may affect periodontal membrane and alveolar bone loss leading to periodontitis. The negative effects of formaldehyde were described using vascular endothelial growth factor (VEGF), matrix metallopeptidase 2 (MMP-2) and osteonectin antibodies involved in the extracellular matrix and angiogenetic development.

Materials and methods: Thirty adult Wistar albino rats were used in this study. Rats were divided into two groups: a control group $(n=15)$ and formaldehyde administered group $(n=15)$. Formaldehyde group was exposed to inhalation of $10 \mathrm{ppm}$ formaldehyde 8 hours a day, 5 days a week for 5 weeks. Maxillary bone regions were dissected under anaesthesia. After fixation in 10\% formaldehyde solution, tissues were passed through graded ethanol series to obtain paraffin blocks. Five-micrometre histological sections were cut with RM2265 rotary microtome stained with Masson trichrome and VEGF, MMP-2 and osteonectin antibodies for examination under Olympus $\mathrm{BH}-2$ light microscopy.

Results: The present study revealed that congestion in blood vessels, degeneration of collagen fibres and alveolar matrix around alveolar bone were observed to be more significant in formaldehyde group than the control group ( $p \leq 0.001)$. Interestingly, VEGF expression in the formaldehyde group was the most significant finding between the two groups $(p<0.001)$. When compared inflammation, MMP-2 and osteonectin expressions were significant $(p<0.01)$ in the formaldehyde group. Conclusions: It was suggested that formaldehyde toxicity decreased the expression of MMP-2 and in osteoblasts as well as affecting the retention of MMP levels in tooth cavity, which is very low in collagen fibres. But, vice versa for the expression of VEGF in dilated vascular endothelial cells and osteocytes in alveolar bone. As a conclusion, formaldehyde disrupts the periodontal membrane and may cause collagen fibres degeneration by affecting the alveolar bone matrix. (Folia Morphol 2019; 78, 3: 545-553)

Key words: periodontal membrane, alveolar bone, formaldehyde, immunohistochemistry 


\section{INTRODUCTION}

Periodontal disease is caused by bacteria in dental plaque, the sticky substance that forms on your teeth a couple of hours after you have brushed. Interestingly, it is your body's response to the bacterial infection that causes most of the dental problems. In an effort to eliminate the bacteria, the cells of our immune system release substances that cause inflammation and destruction of the gums, periodontal ligament or alveolar bone. This leads to swollen, bleeding gums, signs of gingivitis (the earliest stage of periodontal disease), and loosening of the teeth, a sign of severe periodontitis. Studies on periodontitis stated that it is a chronic destructive disease characterised by inflammation of the supporting tissues of the teeth, resulting in periodontal tissue damage and alveolar bone loss [15, 24]. As periodontitis is one of the most prevalent diseases several studies were reported to investigate its pathogenesis through the combination of experimental models $[6,9,12,16,18,26]$.

Formaldehyde is highly soluble in water, as well as in most organic solvents, and is a highly reactive molecule that can be irritating to tissues through direct contact. Formaldehyde causes cytotoxicity through the formation of strong DNA-protein cross-links, as well as cross-links with other molecules, e.g., amino acids [23]. Formaldehyde is used in household products, glues and as industrial fungicide, germicide, and disinfectant. It is commonly used as a preservative in mortuaries and tissue fixation in medical laboratories. It is a highly endogenous chemical substance of which workers from different jobs in a broad perspective are frequently exposed to. Exogenously, formaldehyde can be absorbed after inhalative, dermal and oral exposure and the amount of absorption is dependent on the route of exposure. The overall uptake of inhaled formaldehyde by the nasal passages at resting minute volume airflow rates has been predicted to be $90 \%$ in rats, $67 \%$ in monkeys and $76 \%$ in human [17]. A study on workers suggested that long-term exposure to formaldehyde can cause leucopoenia and another one reported that a significantly higher percentage of formaldehyde-exposed workers had blood cell abnormalities (leucopoenia, thrombocytopoenia, and depressed serum haemoglobin levels) compared with unexposed controls [29].

In periodontal disease, there is collagen degradation leading to gingival and supporting tissue destruction and finally deterioration of teeth occurs [13]. Collagen fibres are composed of protein and proteins have the affinity to react with formaldehyde. Formaldehyde reacts with primary amines to form Schiff bases, with amides to form toxic hydroxymethyl compounds [30]. The degradation of the gingival tissue in periodontitis may be a result of cell-cell and cell-matrix interactions, including enzyme activities like endopeptidases. It is known that endopeptidases are responsible for the tissue degradation process. Matrix metalloproteinases (MMPs) are endopeptidases produced by different types of gingival cells and contribute to tissue breakdown [28]. MMP plays an important role in the inflammation during periodontal disease as it hydrolyses different proteoglycans and glycosaminoglycans, such as Syndecan $1[1,19]$. Excessive production of MMP-2 because of genetic polymorphisms may influence the manifestation and development of periodontal diseases [22]. In particular resident, periodontal ligament and gingival fibroblasts was reported to secrete MMP-2 and chemoattractants for epithelial cells [12].

Osteonectin is a $32 \mathrm{kDa}$ phosphorylated glycoprotein. Evidence that SPARC/osteonectin contributes to human periodontal disease is supported by significant increases in SPARC/osteonectin expression detected in the gingival crevicular fluid of patients with periodontal disease [18]. Vascular endothelial growth factor (VEGF) potently regulates the formation of new blood vessels through VEGF receptors and has been reported to be a key factor in periodontal angiogenesis during tooth movement [25].

The purpose of this study is to investigate the effects of formaldehyde on periodontal membrane and alveolar bone which may lead to periodontitis when inhaled, using immunohistochemical methods for VEGF, MMP-2 and osteonectin observed in extracellular matrix composition and angiogenetic development.

\section{MATERIALS AND METHODS}

\section{Animals and experimental design}

All surgical procedures and the subsequent care and treatment of the animals used in this study were in strict accordance with the National Institutes of Health (NIH) guidelines for animal care (NIH Publication no. 85-23, revised 1996). All procedures performed in this experiment were approved by the Ethics Committee for the Treatment of Experimental Animals (Faculty of Medicine, University of Dicle, Turkey). Thirty Wistar Albino rats (9 weeks old, 180-200 g) were maintained under $22 \pm 1^{\circ} \mathrm{C}$ and $12 \mathrm{~h}$ light/dark cycles with ad libitum access to standard pelleted food and water. The 30 rats were divided into two groups as control and formaldehyde groups. All the animals were individually 
housed in stainless steel cages at room temperature. The rats of the control $(n=15)$ were only administered $1.5 \mathrm{~mL}$ physiologic saline solution subcutaneously. Formaldehyde group was exposed to inhalation of 10 ppm formaldehyde 8 hours a day, 5 days a week for 5 weeks. Formaldehyde vapour in the environment, with a special air pump ventilation constant volume, pressure and temperature achieved [4]. The rats of all groups were maintained in the same conditions. All rats at the end of the experiment were healthy and no difference in food/water consumption and body weight gain between experimental and control rats were observed. At the end of the study, the animals were sacrificed using a decapitator (Harvard Apparatus, Holliston, MA, USA).

\section{Histologic examinations}

The maxillary regions were dissected under ketamine hydrochloride anaesthesia and placed in 10\% formaldehyde solution. They were placed in paraffin inclusion melted at $58^{\circ} \mathrm{C}$ after treatment with xylole, the 4-6 $\mu \mathrm{m}$ sections were taken by rotary microtome (Rotatory Microtome, Leica, RM 2265, Germany) and the sections were stained with Masson trichrome stain. Periodontal membrane and alveolar bone of maxilla sections were examined histopathologically and immunohistochemically.

\section{Immunohistochemical staining}

Sections were brought to distilled water and washed in $3 \times 5$ min phosphate buffered saline (PBS). Catalogue number 10010023, Thermo Fischer Scientific Fremont, CA, USA. Antigen retrieval was done in microwave (Bosch ${ }^{\circledR}, 700$ watt) for $3 \mathrm{~min} \times 90^{\circ} \mathrm{C}$. They were subjected to a heating process in a microwave oven at 700 watts in a citrate buffer (pH 6) solution for proteolysis. Sections were washed in $3 \times 5$ min PBS and incubated with hydrogen peroxide (K-40677109, 64271 hydrogen peroxide $\left[\mathrm{H}_{2} \mathrm{O}_{2}\right.$ ], Dortmund, Germany, MERCK; $3 \mathrm{~mL} 30 \%$ hydrogen peroxide $\left[\mathrm{H}_{2} \mathrm{O}_{2}\right]+27 \mathrm{~mL}$ methanol) for $20 \mathrm{~min}$. Sections were washed in $3 \times 5$ min PBS min and blocked with Ultra V Block (lot: PHL150128, Thermo Fischer, Fremont, CA, USA) for $8 \mathrm{~min}$. After draining, primary antibodies were directly applied to sections distinctly (VEGF, 1:100, lot\#MA5-12184, Thermo Fischer, Fremont, CA, USA; MMP-2 monoclonal antibody 1:100, CA719E3C Thermo Fischer, Fremont, CA, USA; osteonectin, SPARC, Catalogue \#: 33-5500, 1:100, Thermo Fischer, Fremont, CA, USA). Sections were incubated and left overnight at $4^{\circ} \mathrm{C}$. Sections were washed in $3 \times 5$ min PBS and then incubated with Biotinylated Secondary Antibody (lot: PHL150128, Thermo Fischer, Fremont, CA, USA) for $14 \mathrm{~min}$. After washing with PBS, Streptavidin Peroxidase (lot: PHL150128, Thermo Fischer, Fremont, CA, USA) was applied to sections for $15 \mathrm{~min}$. Sections were washed in $3 \times 5 \mathrm{~min}$ PBS and DAB (lot: HD36221, Thermo Fischer, Fremont, CA, USA) were applied to sections up to $10 \mathrm{~min}$. Slides showing reaction was stopped in PBS. Counter staining was done with Harris's haematoxylin for $45 \mathrm{~s}$, dehydrated through ascending alcohol and cleared in xylene. Product number: HHS32 SIGMA, haematoxylin solution, Harris Modified, Sigma-Aldrich, 3050 Spruce Street, Saint Louis, MO 63103, USA. Slides were mounted with Entellan ${ }^{\circledR}$ (lot: 107961, Sigma-Aldrich, St. Louis, MO, USA) and examined under Olympus $\mathrm{BH}-2$ light microscopy.

All morphological changes; congestion in blood vessels, inflammation, damage of collagen fibres, alveolar matrix, VEGF, osteonectin and MMP-2 expression were noted. The intensity of these changes were graded from 0 to 6 ( 0 - no change, 1 - low, $2-$ intermediate, 3-4 - moderate, 5-6 - intense) [34].

\section{Statistical analysis}

Statistical analysis was performed with the Statistical Package for the Social Sciences for Windows (version 15.0, SPSS Inc., Chicago, IL, USA). The Mann-Whitney $U$ test was used for the statistics as indicated, test and results were expressed as mean \pm standard deviation. $P$ values below 0.05 were considered to indicate statistical significant.

\section{RESULTS}

\section{Histological analysis}

The histopathological results of the present study were evaluated under light microscope. There were no histopathological changes in the control group. We compared histopathological findings and primer antibodies' expressions in the control and formaldehyde groups (Table 1 and Graph 1).

Results of the study indicated that congestion in blood vessels, degeneration of collagen fibres and alveolar matrix around alveolar bone were observed to be more significant in formaldehyde group than the control group ( $p \leq 0.001$ ). Interestingly, VEGF expression in the formaldehyde group was the most significant difference between the two groups $(p<0.001)$. Inflammation, MMP-2 and osteonec- 
Table 1. Histopathological scoring of the control and formaldehyde group.

\begin{tabular}{|c|c|c|c|}
\hline & Control (n = 15) & Formaldehyde $(n=15)$ & $\mathbf{P}$ \\
\hline Congestion in blood vessels & $0.01 \pm 0.02$ & $6.0 \pm 0.01$ & $\leq 0.001^{* *}$ \\
\hline Inflammation & $0.18 \pm 0.31$ & $4.80 \pm 0.50$ & $<0.01^{*}$ \\
\hline Damage of collagen fibres & $0.0 \pm 0.0$ & $2.70 \pm 0.10$ & $\leq 0.001^{* *}$ \\
\hline Alveolar matrix & $0.01 \pm 0.02$ & $3.0 \pm 0.02$ & $\leq 0.001^{* *}$ \\
\hline VEGF expression & $1.53 \pm 0.5$ & $4.53 \pm 0.61$ & $<0.001^{* * *}$ \\
\hline MMP-2 expression & $3.62 \pm 0.3$ & $0.82 \pm 0.4$ & $<0.01^{*}$ \\
\hline Osteonectin expression & $2.62 \pm 0.3$ & $0.74 \pm 0.6$ & $<0.01^{*}$ \\
\hline
\end{tabular}

Values are presented as mean \pm standard deviation. Mann-Whitney U test was performed. ${ }^{* *} p<0.001$ vs. control; ${ }^{* *} p \leq 0.001$ vs. control; ${ }^{*} p<0.01$ vs. control; MMP-2 - matrix metallopeptidase 2; VEGF — vascular endothelial growth factor

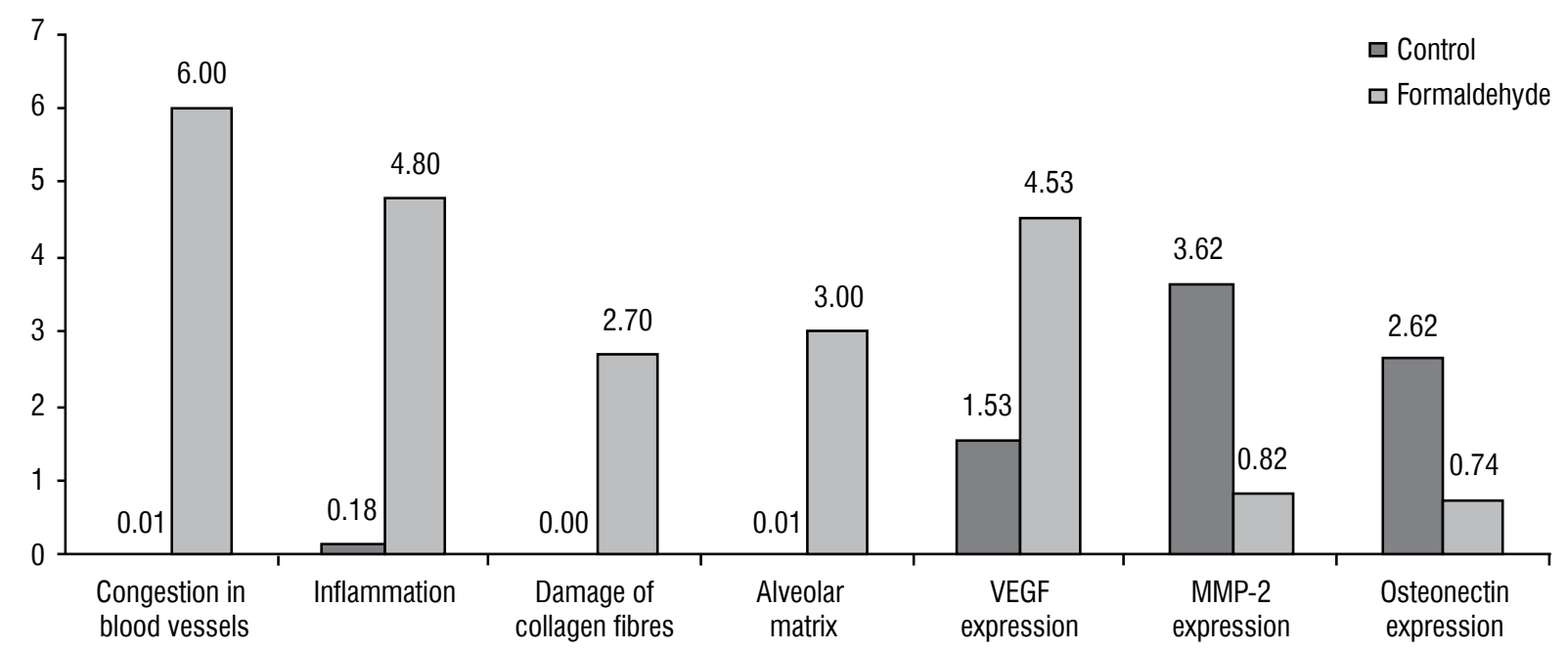

Graph 1. Histopathological difference and primer antibodies' expressions in the control and formaldehyde groups (scoring was determined in the periodontal membrane and alveolar process of maxillary sections in 15 different regions within the microscope field); MMP-2 - matrix metallopeptidase 2; VEGF — vascular endothelial growth factor.

tin expressions were statistically significantly higher $(p<0.01)$ in the formaldehyde group when compared to the control group.

In the transverse section taken from the maxillary region, particularly in the periodontal ligament extending to the alveolar bone of molar teeth, parallelly arranged fusiform fibroblasts occupied collagen fibres and there was no increase in the amount of connective tissue, and the capillary structure was observed to be normal (Fig. 1a). In the formaldehyde group, both thickening and degeneration of collagen fibres around alveolar bone were observed. Hyperplasic fibroblast cells, congested blood vessels and mononuclear cell filtration around vessels were observed (Fig. 1b). In the control group, VEGF expression in the vascular endothelial cells of the periodontal membrane was positive while it was negative in the osteocytes of the alveolar bone (Fig. 2a). In the neg- ative control of the same section, VEGF expression was negative in endothelial cells and osteocytes (Fig. 2a*). In the formaldehyde group, VEGF expression in dilated vascular endothelial cells was increased and VEGF was also positively expressed observed in osteocytes in alveolar bone (Fig. 2b, Graph 1). In the negative control of the same section, expression was negative in osteocytes of alveolar bone (Fig. $2 b^{*}$ ). Therefore, it was thought formaldehyde can induce angiogenesis. When MMP-2 levels were examined in the control group, MMP-2 expression was observed in the collagen fibrils and fibroblast cells of the periodontal membrane (Fig. 3a, Graph 1). In the negative control of the same section, expression was negative in the collagen fibrils and fibroblast cells of the periodontal membrane (Fig. 3a*). In the formaldehyde group, no MMP-2 expression in the collagen fibres of periodontal membrane and fibroblast cells with 

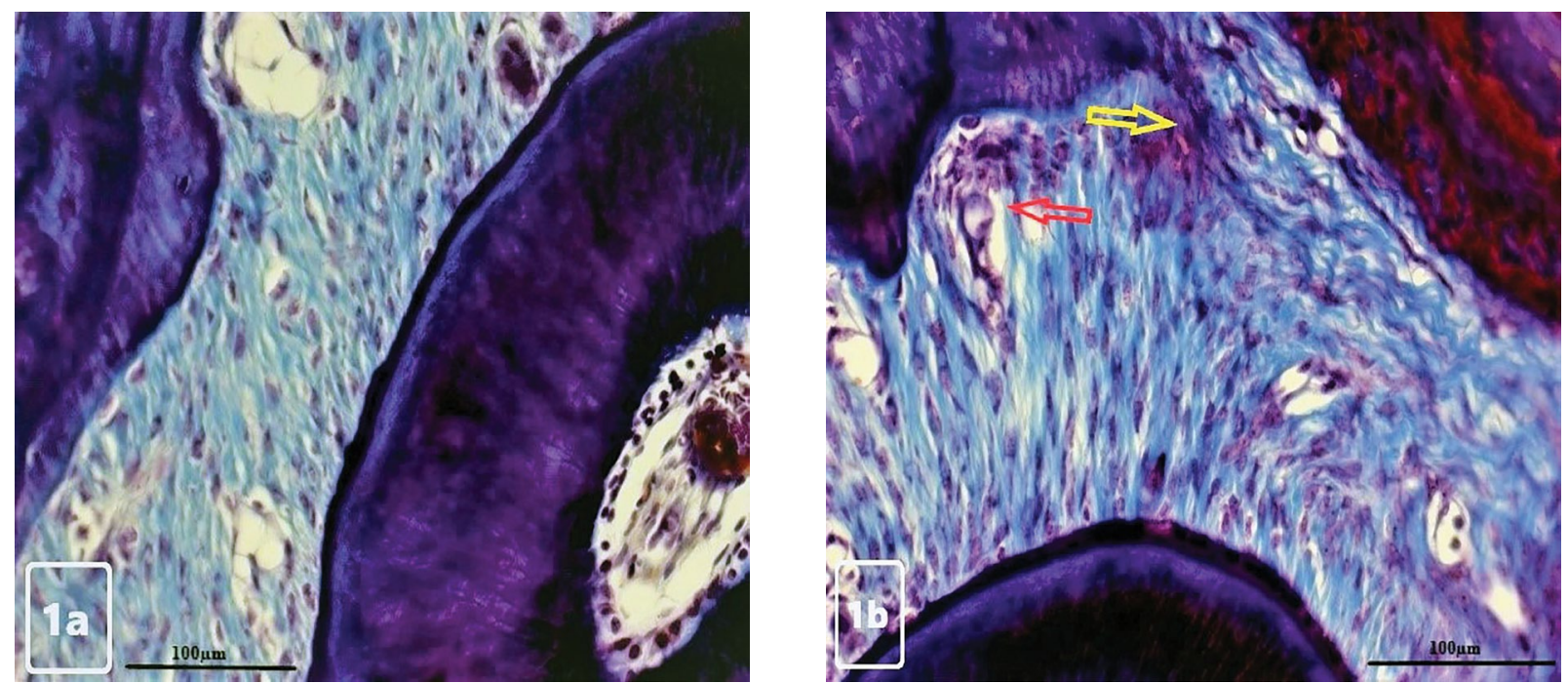

Figure 1. a. Trichrom-Masson staining, the control group. Normal appearance of alveolar bone and periodontal ligament structure. Scale bar $=$ $100 \mu \mathrm{m} ; \mathbf{b}$. Trichrom-Masson staining, the formaldehyde group. Degeneration of collagen fibres around alveolar bone (yellow arrow), dilatation and congestion of blood vessels, mononuclear infiltration in periodontal ligament (red arrow). Scale bar $=100 \mu \mathrm{m}$.
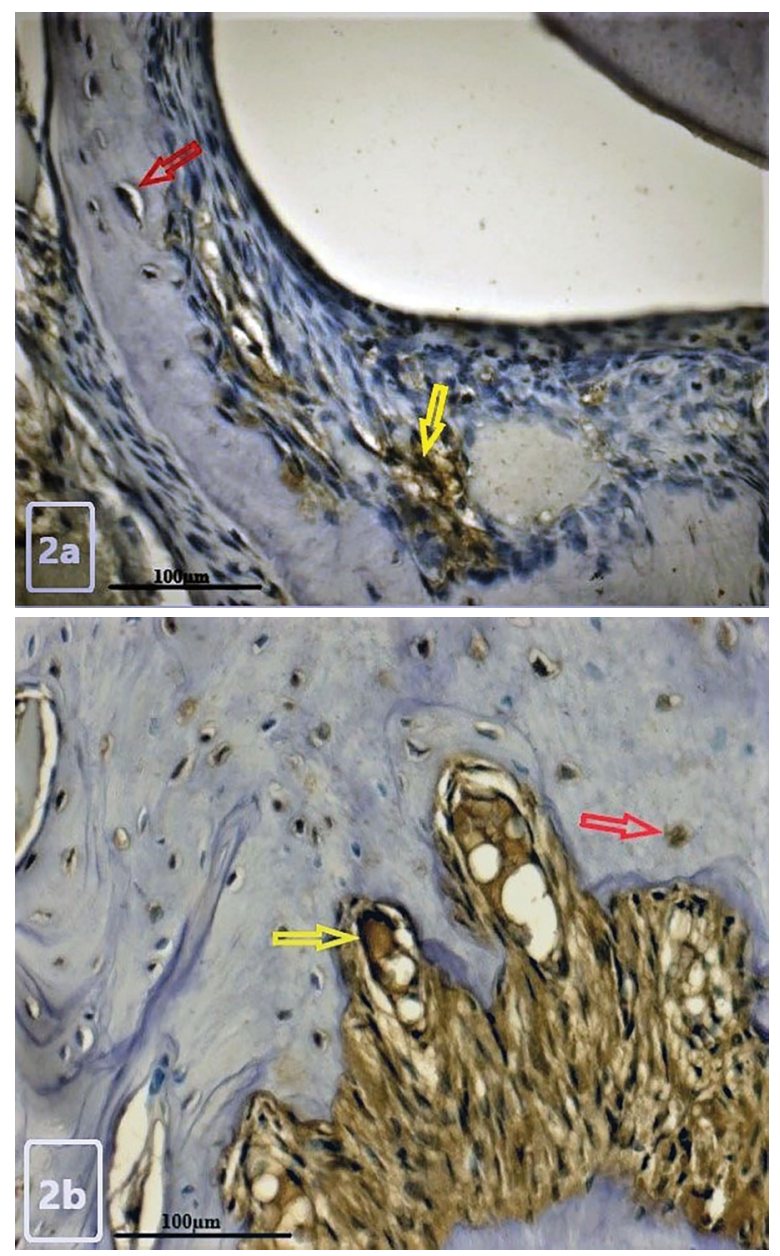
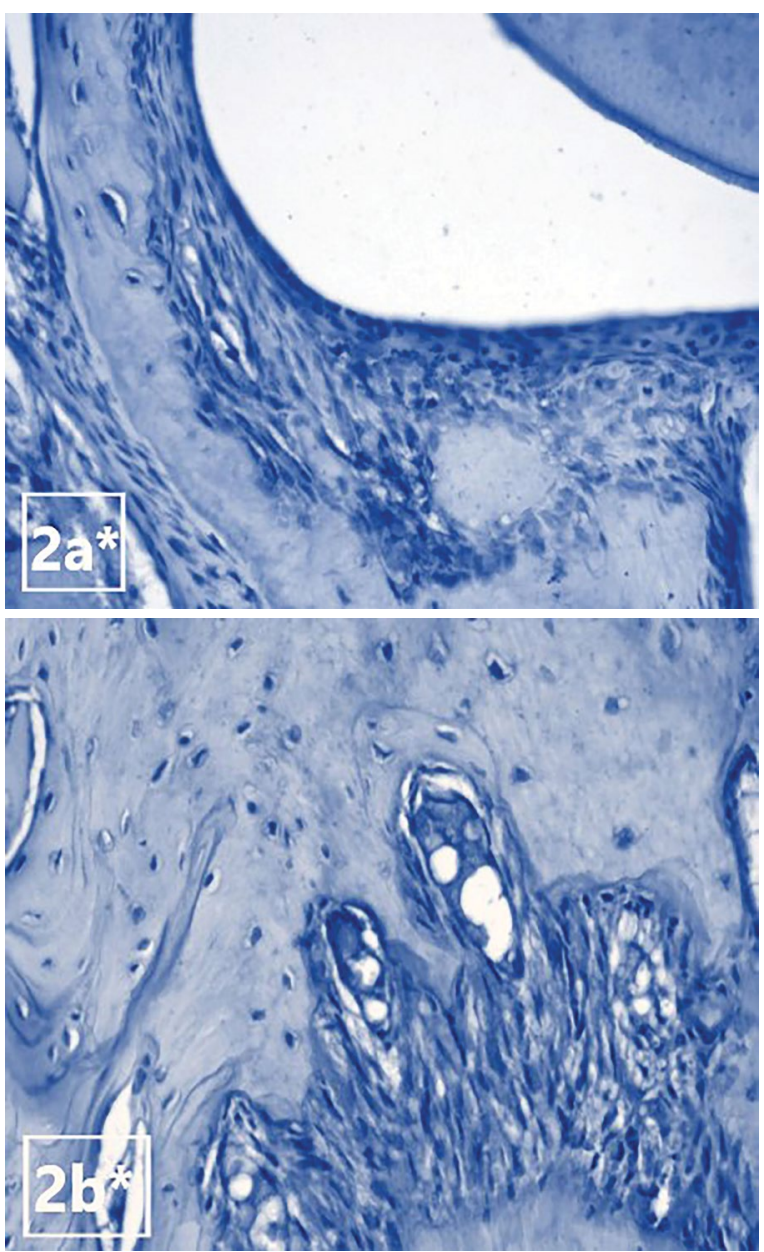

Figure 2. a. Vascular endothelial growth factor (VEGF) immunostaining, the control group. Positive VEGF expression in the vascular endothelial cells of the periodontal membrane (yellow arrow), negative VEGF expression in the osteocytes of the alveolar bone (red arrow). Scale bar $=100 \mu \mathrm{m}$; $\mathbf{a}^{*}$. Negative control, haematoxylin staining. Scale bar $=100 \mu \mathrm{m} ; \mathbf{b}$. VEGF immunostaining, the formaldehyde group. An increase VEGF expression in vascular endothelial cells (yellow arrow) positive VEGF expression in osteocytes in alveolar bone, (red arrow). Scale bar $=100 \mu \mathrm{m}$; b* $^{*}$. Negative control, haematoxylin staining. Scale bar $=100 \mu \mathrm{m}$. 

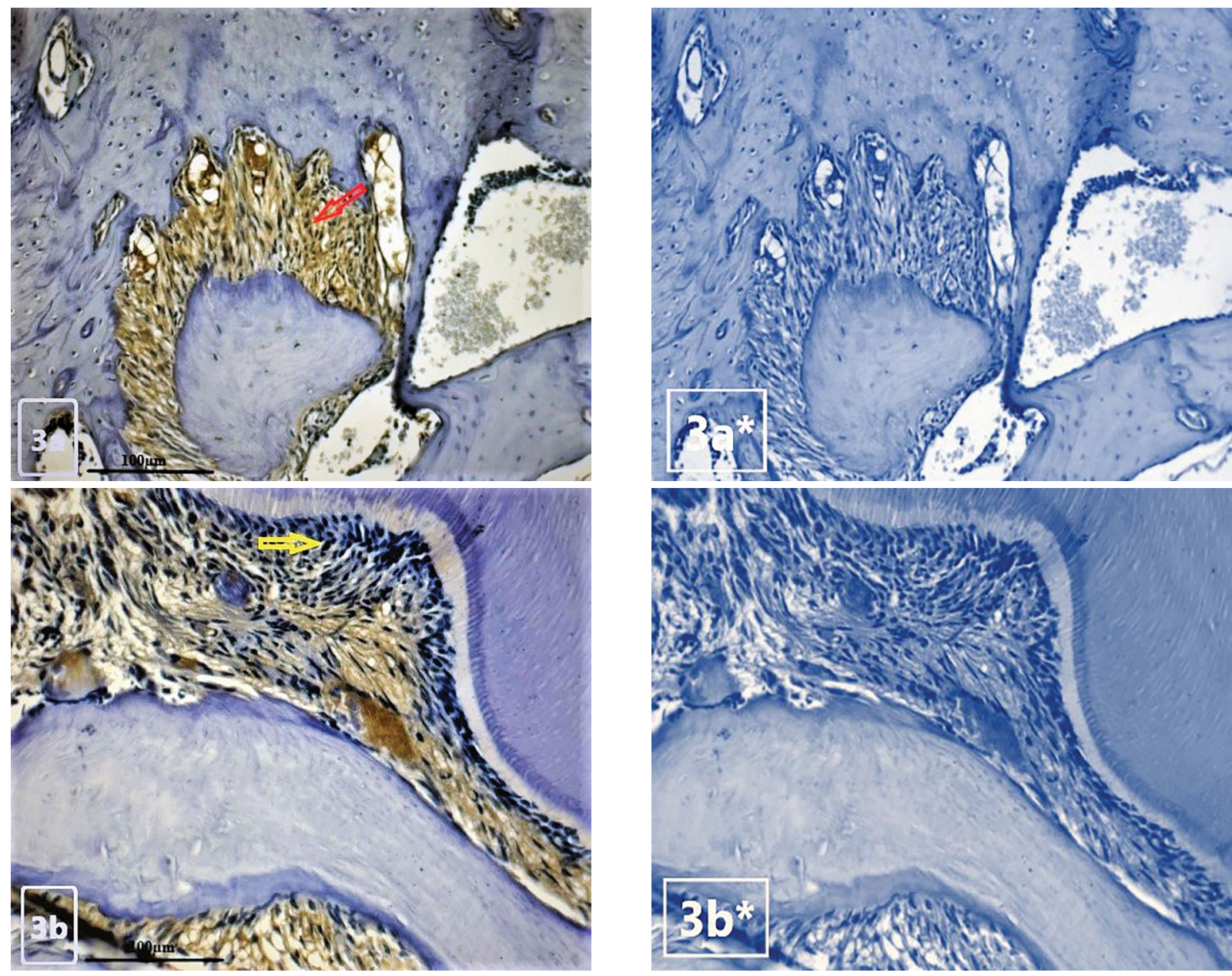

Figure 3. a. Matrix metallopeptidase 2 (MMP-2) immunostaining, the control group. Positive MMP-2 expression in the collagen fibres and fibroblast cells of the periodontal membrane (red arrow). Scale bar $=100 \mu \mathrm{m} ; \mathbf{a}^{*}$. Negative control, haematoxylin staining. Scale bar $=100 \mu \mathrm{m}$; b. MMP-2 immunostaining, the formaldehyde group. Negative MMP-2 expression in the collagen fibres of periodontal membrane and fibroblast cells (yellow arrow). Scale bar $=100 \mu \mathrm{m} ; \mathbf{b}^{*}$. Negative control, haematoxylin staining. Scale bar $=100 \mu \mathrm{m}$.

degenerative fibres were seen (Fig. 3b). The negative control of the same section is shown in Figure $3 \mathrm{~b}^{*}$. In the control group, positive osteonectin expression in the periodontal membrane and alveolar bone was observed (Fig. 4a, Graph 1), and it was decreased especially in the bone matrix and colloidal fibres. In the negative control of the same section, osteonectin expression was negative in the periodontal membrane and alveolar bone (Fig. 4a*). This phenomenon was clearly observed between the alveolar bone and periodontium (Fig. 4b). The negative control of the same section is shown in Figure $4 b^{*}$.

\section{DISCUSSION}

Formaldehyde is a highly toxic substance, especially when inhaled, which affects the nasal and oral cavities. In a study of Bansal et al. [5] on rabbits, it was stated that even the short term exposure ( 6 weeks) of concentrated vapours of formaldehyde ( $40 \%$ solution) cause an irritant effect on the respiratory tract and alters its functional activity and cellular morphology. Cell proliferation is increased by 5 days of inhalation at 6 ppm formaldehyde and microarray analysis shows the expression of 15 genes were altered by 5 days of inhalation at $2 \mathrm{ppm}$ formaldehyde [33].

Yorgancilar et al. [33] reported that inhalation of formaldehyde resulted in nasal mucosa and connective tissue inflammation, as well as other structures in the nasal cavity, which may increase rhinitis. In our study, remarkably increased inflammation in the maxillary region, altered fibrous structure in the periodontal region and developed cellular infiltration were observed. In a previous study it was reported that 16-day and 13-week inhalation studies with glutaraldehyde in rats and mice, the nose was the primary target site [31]. Lesions in the nasal cavity included hyperplasia, 

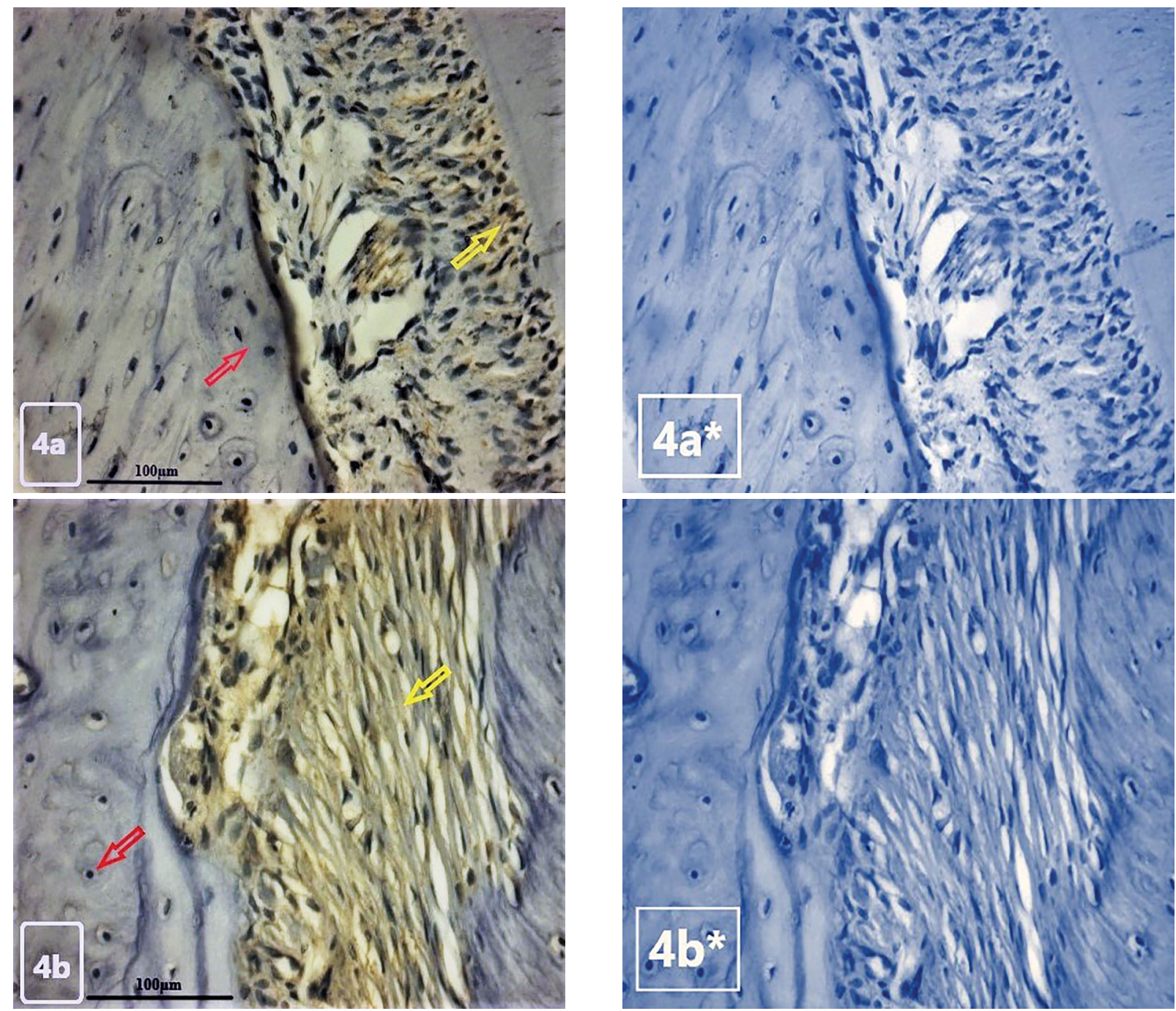

Figure 4. a. Osteonectin immunostaining, the control group. Expression of osteonectin in fibroblast cells and collagen fibres of the periodontal membrane (yellow arrow), and osteonectin expression in the bone matrix (red arrow). Scale bar $=100 \mu \mathrm{m}$; $\mathbf{a}^{*}$. Negative control, haematoxylin staining. Scale bar $=100 \mu \mathrm{m} ; \mathbf{b}$. Osteonectin immunostaining, the formaldehyde group. Negative expression of osteonectin in the periodontal membrane (yellow arrow) negative expression of osteonectin in osteocyte cells of alveolar bone (red arrow). Scale bar $=100 \mu \mathrm{m}$; b*. Negative control, haematoxylin staining. Scale bar $=100 \mu \mathrm{m}$.

squamous metaplasia, necrosis, and acute inflammation. It was thought that all these could affect the alveolar bone structure by inducing periodontitis development. In periodontal disease, there is collagen degradation; so, deterioration develops in gingival tissue with the supporting apparatus [13]. The collagen is the major extracellular matrix component of gingiva [2]. So, collagen as a protein have the affinity to react with formaldehyde forming toxic hydroxymethyl compounds [30], which means that being exposed to formaldehyde, gingival tissue with the binding structures, for example periodontal ligaments of teeth, are degenerated. Our results also indicated the degeneration of collagen fibres around alveolar bone (Fig. 1b) that may cause teeth loss ultimately.
SPARC/osteonectin production in bones is substantial and is also expressed in cementum, the outer layer of the tooth connecting to the periodontal ligament (PDL). Periodontal disease is difficult to treat because of the associated bone loss that occurs when the PDL is degraded. Osteonectin production in bones is substantial and is also expressed in cementum, the outer layer of the tooth connecting to the PDL $[3,14]$. In the current investigation, with immunohistochemical methods, it was identified to be decreased especially in the bone matrix and colloidal fibres. This phenomenon was clearly observed between the alveolar bone and periodontium.

Matrix metalloproteinases hydrolyse components of the extracellular matrix. Although the activity of MMPs has been shown to be essential in cell biolog- 
ical processes and many fundamental physiological events involving tissue remodelling, such as angiogenesis, bone development, wound healing and mammary involution [35].

Several MMPs have been identified in the inflamed gingival tissues: MMP-1, $-2,-3,-8,-9,-13$, produced by the keratinocytes, macrophages, polymorphonuclear leukocytes $[4,7,11,35]$. Their activity could be different depending on the severity of disease and the needs for extracellular matrix digestion. In some cases, MMP-1 expression extended to the lamina propria as inflammation progressed. MMP-1 increased activity could explain the change of collagen quality and quantity, since its preferred substrates are the type I and type III collagens [20]. Several other researchers reported an intense MMP-1 collagenolytic activity in fibroblasts and macrophages resident in the periodontal tissue $[21,27]$ and focused on the interrelation between MMP-1 and MMP-3 in order to amplify the proteolysis in chronic periodontitis [7]. It has been reported that the induction of MMPs (such as MMP-2) in osteoblasts is essential for bone resorption. Excessive production of MMP-2, combined with the selective production of MMP-9, can lead to the acceleration of matrix degradation in pathological conditions such as periodontitis [8]. In our study, no MMP-2 expression in the collagen fibres of periodontal membrane and fibroblast cells was observed in the formaldehyde administered group perhaps in the meaning of osteoblastic activity due to formaldehyde toxicity leading to matrix degeneration and impaired the collagen fibre structure which encouraged periodontitis.

Vascular endothelial growth factor is a key regulator of physiological and pathological angiogenesis, because it induces endothelial cell proliferation, stimulates angiogenesis and increases vascular permeability. VEGF immunoreactivity was seen in vascular endothelial cells, osteoblasts, osteoclasts in resorption lacunae, in fibroblasts adjacent to hyalinised tissue, a local necrotic area in compressed zone, and in mononuclear cells in periodontal tissues of experimental animals [25]. In periodontitis patients, VEGF was detected within vascular endothelial cells, neutrophils, plasma cells, and junctional, pocket and gingival epithelium $[10,32]$. According to our examinations, VEGF expression was positive in the vascular endothelial cells of periodontal membrane, but negative in the osteocytes of the alveolar bone in the control group. On the other hand, in the formaldehyde group, VEGF expression was positive in dilated vascular endothelial cells and also in osteocytes in alveolar bone. These results suggested that formaldehyde may induce angiogenesis.

\section{CONCLUSIONS}

In the formaldehyde group, VEGF expression was positive in two significant regions: in dilated vascular endothelial cells and in osteocytes of the alveolar bone, as a regulator of vasculogenesis and angiogenesis and a potent inducer of vascular permeability. Formaldehyde toxicity may be a consequence of decreased expression of MMP-2 in osteoblasts as well as affecting the retention of MMP levels in tooth cavity, which is very low in colloid fibres. It is thought that long term formaldehyde inhalation may disrupt the periodontal membrane and cause collagen fibre degeneration by affecting the alveolar bone matrix which may lead to periodontitis.

\section{REFERENCES}

1. Alexopoulou AN, Multhaupt HAB, Couchman JR. Syndecans in wound healing, inflammation and vascular biology. Int J Biochem Cell Biol. 2007; 39(3): 505-528, doi: 10.1016/j. biocel.2006.10.014, indexed in Pubmed: 17097330.

2. Almeida T, Valverde T, Martins-Júnior $P$, et al. Morphological and quantitative study of collagen fibers in healthy and diseased human gingival tissues. Rom J Morphol Embryol. 2015; 56(1): 33-40, indexed in Pubmed: 25826485.

3. Andersen ME, Clewell HJ, Bermudez E, et al. Genomic signatures and dose-dependent transitions in nasal epithelial responses to inhaled formaldehyde in the rat. Toxicol Sci. 2008; 105(2): 368-383, doi: 10.1093/toxsci/kfn097, indexed in Pubmed: 18499655.

4. Baniță M, Pisoschi C, Stănciulescu C, et al. Phenytoin-induced gingival overgrowth: an immunohistochemical study of TGF- $\beta 1$ mediated pathogenic pathways. Farmacia. 2011; 59(1): 24-33, doi: 10.5772/59267.

5. Bansal N, Uppal V, Pathak D. Toxic effect of formaldehyde on the respiratory organs of rabbits: a light and electron microscopic study. Toxicol Ind Health. 2011; 27(6): 563-569, doi: 10.1177/0748233710393398, indexed in Pubmed: 21343228.

6. Bartold PM, Narayanan AS. Molecular and cell biology of healthy and diseased periodontal tissues. Periodontol 2000. 2006; 40: 29-49, doi: 10.1111/j.16000757.2005.00140.x, indexed in Pubmed: 16398684.

7. Bartold PM, Narayanan AS. Molecular and cell biology of healthy and diseased periodontal tissues. Periodontol 2000. 2006; 40: 29-49, doi: 10.1111/j.16000757.2005.00140.x, indexed in Pubmed: 16398684

8. Beklen A, Ainola M, Hukkanen M, et al. MMPs, IL-1, and TNF are regulated by IL-17 in periodontitis. J Dent Res. 2007; 86(4): 347-351, doi: 10.1177/154405910708600 409, indexed in Pubmed: 17384030.

9. Bildt MM, Bloemen M, Kuijpers-Jagtman AM, et al. Collagenolytic fragments and active gelatinase complexes in periodontitis. J Periodontol. 2008; 79(9): 1704-1711, doi: 10.1902/jop.2008.080021, indexed in Pubmed: 18771372. 
10. Booth V, Young S, Cruchley A, et al. Vascular endothelial growth factor in human periodontal disease. J Periodontal Res. 1998; 33(8): 491-499, indexed in Pubmed: 9879523.

11. Delany AM, Hankenson KD. Thrombospondin-2 and SPARC/ osteonectin are critical regulators of bone remodeling. J Cell Commun Signal. 2009; 3(3-4): 227-238, doi: 10.1007/ s12079-009-0076-0, indexed in Pubmed: 19862642.

12. Giannobile WV. Host-response therapeutics for periodontal diseases. J Periodontol. 2008; 79(8 Suppl): 1592-1600, doi: 10.1902/jop.2008.080174, indexed in Pubmed: 18673015.

13. Golijanin R, Kujundžić B, Milosavljević Z, et al. Morphometric analysis of collagen and inflammatory cells in periodontal disease. Vojnosanit Pregl. 2015; 72(3): 219-224, indexed in Pubmed: 25958472.

14. Gross EA, Mellick PW, Kari FW, et al. Histopathology and cell replication responses in the respiratory tract of rats and mice exposed by inhalation to glutaraldehyde for up to 13 weeks. Fundam Appl Toxicol. 1994; 23(3): 348-362, indexed in Pubmed: 7835535.

15. Irfan UM, Dawson DV, Bissada NF. Epidemiology of periodontal disease: a review and clinical perspectives. J Int Acad Periodontol. 2001; 3(1): 14-21, indexed in Pubmed: 12666973 .

16. Jearanaiphaisarn T, Sanharati T, Pavasant $P$, et al. The effect of iloprost on cell proliferation and angiogenesis-related gene expression in human periodontal ligament cells. Odontology. 2018; 106(1): 11-18, doi: 10.1007/s10266017-0307-4, indexed in Pubmed: 28547570.

17. Kimbell JS, Subramaniam RP, Gross EA, et al. Dosimetry modeling of inhaled formaldehyde: comparisons of local flux predictions in the rat, monkey, and human nasal passages. Toxicol Sci. 2001; 64(1): 100-110, doi: 10.1093/toxsci/64.1.100, indexed in Pubmed: 11606806.

18. Kinney JS, Ramseier CA, Giannobile WV. Oral fluid-based biomarkers of alveolar bone loss in periodontitis. Ann N Y Acad Sci. 2007; 1098: 230-251, doi: 10.1196/annals.1384.028, indexed in Pubmed: 17435132.

19. Kotsovilis S, Tseleni-Balafouta S, Charonis A, et al. Syndecan-1 immunohistochemical expression in gingival tissues of chronic periodontitis patients correlated with various putative factors. J Periodontal Res. 2010; 45(4): 520-531, doi: 10.1111/j.1600-0765.2009.01267.x, indexed in Pubmed: 20412418.

20. Kubota T, Itagaki M, Hoshino C, et al. Altered gene expression levels of matrix metalloproteinases and their inhibitors in periodontitis-affected gingival tissue. J Periodontol. 2008; 79(1): 166-173, doi: 10.1902/jop.2008.070159, indexed in Pubmed: 18166107.

21. Kumar MS, Vamsi G, Sripriya R, et al. Expression of matrix metalloproteinases (MMP-8 and -9) in chronic periodontitis patients with and without diabetes mellitus. J Periodontol. 2006; 77(11): 1803-1808, doi: 10.1902/ jop.2006.050293, indexed in Pubmed: 17076603.

22. Lee W, Aitken S, Sodek J, et al. Evidence of a direct relationship between neutrophil collagenase activity and periodontal tissue destruction in vivo: role of active enzyme in human periodontitis. J Periodontal Res. 1995; 30(1): 23-33, indexed in Pubmed: 7722844.

23. Metz B, Kersten GFA, Hoogerhout $P$, et al. Identification of formaldehyde-induced modifications in proteins: reactions with model peptides. J Biol Chem. 2004; 279(8): 6235-6243, doi: 10.1074/jbc.M310752200, indexed in Pubmed: 14638685.

24. Michaud DS, Joshipura K, Giovannucci E, et al. A prospective study of periodontal disease and pancreatic cancer in US male health professionals. J Natl Cancer Inst. 2007; 99(2): 171-175, doi: 10.1093/jnci/djk021, indexed in Pubmed: 17228001.

25. Miyagawa A, Chiba M, Hayashi $H$, et al. Compressive force induces VEGF production in periodontal tissues. J Dent Res. 2009; 88(8): 752-756, doi: 10.1177/0022034509341637, indexed in Pubmed: 19734464.

26. Pabst R. Exposure to formaldehyde in anatomy: an occupational health hazard? Anat Rec. 1987; 219(2): 109-112, doi: 10.1002/ar.1092190202, indexed in Pubmed: 3688466.

27. Page-McCaw A, Ewald AJ, Werb Z. Matrix metalloproteinases and the regulation of tissue remodelling. Nat Rev Mol Cell Biol. 2007; 8(3): 221-233, doi: 10.1038/nrm2125, indexed in Pubmed: 17318226.

28. Séguier S, Gogly B, Bodineau A, et al. Is collagen breakdown during periodontitis linked to inflammatory cells and expression of matrix metalloproteinases and tissue inhibitors of metalloproteinases in human gingival tissue? J Periodontol. 2001; 72(10): 1398-1406, doi: 10.1902/ jop.2001.72.10.1398, indexed in Pubmed: 11699482.

29. Tang $X$, Bai $Y$, Duong $A$, et al. Formaldehyde in China: production, consumption, exposure levels, and health effects. Environ Int. 2009; 35(8): 1210-1224, doi: 10.1016/j. envint.2009.06.002, indexed in Pubmed: 19589601.

30. Thavarajah R, Mudimbaimannar VK, Elizabeth J, et al. Chemical and physical basics of routine formaldehyde fixation. J Oral Maxillofac Pathol. 2012; 16(3): 400-405, doi: 10.4103/0973-029X.102496, indexed in Pubmed: 23248474.

31. van Birgelen AP, Chou BJ, Renne RA, et al. Effects of glutaraldehyde in a 2-year inhalation study in rats and mice. Toxicol Sci. 2000; 55(1): 195-205, doi: 10.1093/ toxsci/55.1.195, indexed in Pubmed: 10788574.

32. Yanagita M, Kojima Y, Kubota M, et al. Cooperative effects of FGF-2 and VEGF-A in periodontal ligament cells. J Dent Res. 2014; 93(1): 89-95, doi: 10.1177/0022034513511640, indexed in Pubmed: 24186558.

33. Yorgancilar E, Deveci E, Deveci S. Effects of Formaldehyde on Respiratory Mucosa in Rats. Int J Morphol. 2012; 30(2): 521-523, doi: 10.4067/s0717-95022012000200026.

34. Yorgancilar E, Tunik S, Deveci E, et al. The effects of systemic use of nicotine on the rat nasal mucosa: a histopathologic and Immunohistochemical study. Int J Morphol. 2012; 30(3): 829-833, doi: 10.4067/s071795022012000300010.

35. Zeichner-David M. Regeneration of periodontal tissues: cementogenesis revisited. Periodontol 2000. 2006; 41: 196-217, doi: 10.1111/j.1600-0757.2006.00162.x, indexed in Pubmed: 16686935. 